\title{
A COMPENSAÇÃO AMBIENTAL PREVISTA PELO SISTEMA NACIONAL DE UNIDADES DE CONSERVAÇÃO (SNUC): A ADI No 3.378 E O DECRETO No 6.848/o9
}

\author{
José Marcos Domingues e Júlia Silva Araújo Carneiro
}

\section{RESUMO}

O TRABALHO TRAÇA A TRAJETÓRIA DA COMPENSAÇ̃O ambIENTAL INSTITUÍdA PELA LEI DO SISTEMA NACIONAL DE UNIDADES DE CONSERVAC̣ÃO (SNUC), DA SUA CRIAC̣ÃO, PASSANDO PELO JULGAMENTO DO SUPREMO TRIBUNAL FEDERAL NA ADI N 3.378/DF (QUE A JULGOU PARCIALMENTE INCONSTITUCIONAL, COM REDUCÃO DE TEXTO], ATÉ A ÚLTIMA REgulamentação da matéria PELO PODER ExeCutivo (DECRETO No 6.848, DE 2009), PRETENSAMENTE EM CONSONÂNCIA COM A DECISÃO DA CORTE. DA ANÁLISE DESTE DECRETO, DEPREENDE-SE QUE FORAM PREVISTOS CRITÉRIOS PARA O CÁLCULO DA COMPENSACÃO AMBIENTAL OS QUAIS, NA VERDADE, RETOMAM A NOÇÃO DE PERCENTUAL E VÍNCULO AO CUSTO DO EMPREENDIMENTO IMPACTANTE, EM AFRONTA À DECISÃO PROFERIDA PELO STF, CONFIGURANDO VIOLAÇÃO À Separação de Poderes. Por outro lado, a nova redação DO ART. 31 DO REGULAMENTO ANTERIOR, INTRODUZIDA PELO DECRETO CITADO, PREVÊ A COMPETÊNCIA DO IBAMA, ÓRGÃO FEDERAL DE LICENCIAMENTO AMBIENTAL, PARA A FIXACÃO DO VALOR DA COMPENSAÇÃO, DAÍ SE DEDUZINDO QUE APENAS AOS EMPREENDIMENTOS SUJEITOS A LICENCIAMENTO PELO IBAMA, NO EXERCÍCIO DE COMPETÊNCIA FEDERAL EXCLUSIVA, PODERÁ SER APLICADA A COMPENSAÇÃO AMBIENTAL. EM SÍNTESE, ESTE ENSAIO ANALISA AS INOVAÇÕES TRAZIDAS PELO DECRETO $N^{0}$ 6.848/09, ASSIM COMO SUSTENTA A NATUREZA TRIBUTÁRIA DA COMPENSAÇÃO SNUC, AINDA NÃO DEBATIDA PELO STF, MAS QUE NÃO DEVE SER OLVIDADA.

\section{PALAVRAS-CHAVE}

COMPENSAC̣ÃO AMBIENTAL; COMPENSAC̣ÃO SNUC; REGULAMENTAÇÃO; MEIO AMBIENTE; IMPACTO AMBIENTAL.
THE ENVIRONMENTAL COMPENSATION CONCERNING THE NATIONAL SYSTEM OF CONSERVATION UNITS ("SNUC"): THE UNCONSTITUTIONALITY ACTION ADI N. 3,378 AND THE DECREE N. 6,848/09

\section{ABSTRACT}

THE WORK FEATURES THE ENVIRONMENTAL COMPENSATION ESTABLISHED BY THE LAW ON THE NATIONAL SYSTEM OF CONSERVATION UNITS (SNUC), SINCE ITS CREATION, THE SuPREME COURT RULING OF THE UnCONSTITUTIONALITY DIRECT ACTION-ADI NO 3.378/DF (THAT DECLARED ITS PARTIAL UNCONSTITUTIONALITY WITH TEXT REDUCTION), AND THE LAST REGULATION ON THE MATTER BY THE ADMINISTRATION AS PER DECREE N ${ }^{0}$ 6.848/09, INTENDED TO BE IN HARMONY WITH THE SUPREME COURT DECISION. FROM THE ANALYSIS OF THE DECREE, WE CAN INFER THAT SOME STANDARDS SET FOR THE ENVIRONMENTAL COMPENSATION CALCULATION, IN FACT RETAKE THE NOTION OF A PERCENTAGE RELATED TO THE COST OF THE BUSINESS IMPACTING THE ENVIRONMENT. THEREBY VIOLATING THE SUPREME COURT DECISION AND THE PRINCIPLE OF SEPARATION OF POWERS. ON THE OTHER SIDE, THE NEW TEXT OF ART. 31 OF THE PREVIOUS REGULATION, AS AMENDED BY DECREE N ${ }^{0} 6.948$ PROVIDES FOR THE COMPETENCE OF IBAMA (THE FEDERAL ENVIRONMENTAL AGENCY) FOR DETERMINING THE COMPENSATION AMOUNT, SO THAT ONE MAY CONCLUDE THAT ONLY BUSINESSES THAT DEPEND ON IBAMA'S LICENSING (ACTING ON THE EXERCISE OF ITS EXCLUSIVE FEDERAL COMPETENCE) MAY BE LIABLE FOR THE ENVIRONMENTAL COMPENSATION. SUMMING UP, THE TEXT ANALYZES THE INNOVATION INTRODUCED BY DECREE N ${ }^{0} 6.848$ AND ALSO ADVOCATES THE JURIDICAL NATURE OF A TAX FOR THE SNUC COMPENSATION, WHICH SO FAR HAS NOT BEEN TESTED BY THE SuPREME COURT, ALTHOUgh IT SHOULD NOT BE NEGLECTED.

\section{KEYWORDS}

ENVIRONMENTAL COMPENSATION; SNUC COMPENSATION: REGULATION; ENVIRONMENT; ENVIRONMENTAL IMPACT 


\section{INTRODUÇÃO}

A Lei $\mathrm{n}^{\circ}$ 9.985, de 18 de julho de 2000, que instituiu o Sistema Nacional de Unidades de Conservação (SNUC), previu, em seu artigo 36, uma compensação ambiental devida por ocasião do licenciamento ambiental de empreendimentos que causem significativo impacto ambiental, ou seja, sempre que houver a necessidade da realização de estudo de impacto ambiental e o relatório de impacto ambiental (EIA/RIMA), conforme preceitua o artigo 225, §1 ${ }^{\circ}$, IV, da Constituição Federal. Em sua redação original, assim estabelecia o artigo da Lei 9.985/00:

Art. 36. Nos casos de licenciamento ambiental de empreendimentos de significativo impacto ambiental, assim considerado pelo órgão ambiental competente, com fundamento em estudo de impacto ambiental e respectivo relatório - EIA/RIMA, o empreendedor é obrigado a apoiar a implantação e manutenção de unidade de conservação do Grupo de Proteção Integral, de acordo com o disposto neste artigo e no regulamento desta Lei.

$\S 1^{\circ} \mathrm{O}$ montante de recursos a ser destinado pelo empreendedor para esta finalidade não pode ser inferior a meio por cento dos custos totais previstos para a implantação do empreendimento, sendo o percentual fixado pelo órgão ambiental licenciador, de acordo com o grau de impacto ambiental causado pelo empreendimento.

$\S 2^{\circ}$ Ao órgão ambiental licenciador compete definir as unidades de conservação a serem beneficiadas, considerando as propostas apresentadas no EIA/RIMA e ouvido o empreendedor, podendo inclusive ser contemplada a criação de novas unidades de conservação.

$\S 3^{\circ}$ Quando o empreendimento afetar unidade de conservação específica ou sua zona de amortecimento, o licenciamento a que se refere o caput deste artigo só poderá ser concedido mediante autorização do órgão responsável por sua administração, e a unidade afetada, mesmo que não pertencente ao Grupo de Proteção Integral, deverá ser uma das beneficiárias da compensação definida neste artigo.

Desse modo, a Lei $\mathrm{n}^{\circ}$ 9.985/00 estabeleceu que o empreendedor possui o dever legal de apoiar a implantação e a manutenção de unidade de conservação de proteção integral, através de uma quantia a ser paga a título de compensação, que, conforme o artigo $36, \S 1^{\circ}$, não seria inferior a $0,5 \%$ do custo total do empreendimento. No entanto, não obstante a previsão de um valor mínimo a ser devido, não houve a fixação de um percentual máximo, tendo em vista que este seria definido pelo órgão ambiental, segundo o grau de impacto ambiental causado pelo empreendimento.

Em seguida, o Decreto $\mathrm{n}^{\circ} 4.340$, de 22 de agosto de 2002, veio regulamentar a Lei $n^{\circ} 9.985 / 00$ e, em seus artigos 31 a 34, estabeleceu diretrizes a serem 
seguidas para o pagamento da compensação ambiental. Originalmente, previa o artigo 31 que:

[...] para os fins de fixação da compensação ambiental de que trata o art. 36 da Lei $n^{\circ} 9.985$, de 2000, o órgão ambiental licenciador estabelecerá o grau de impacto a partir dos estudos ambientais realizados quando do processo de licenciamento ambiental, sendo considerados os impactos negativos, não mitigáveis e passíveis de riscos que possam comprometer a qualidade de vida de uma região ou causar danos aos recursos naturais [...]

Sendo certo que, em seu parágrafo único, estabeleceu que a fixação dos percentuais se daria gradualmente, a partir de $0,5 \%$ dos custos totais para implantação do empreendimento, considerando-se a amplitude dos impactos gerados.

Nesse contexto, em 16 de dezembro de 2004, foi ajuizada pela Confederação Nacional das Indústrias (CNI) a ADI $n^{\circ} 3.378$, para impugnar o artigo 36 da Lei 9.985/00 e seus $\S \S 1^{\circ}, 2^{\circ}$ e $3^{\circ}$, alegando, para tanto, que esses dispositivos feririam os princípios da legalidade, da separação de poderes, da razoabilidade e da proporcionalidade.

Em 2005, a redação do caput do artigo 31 do Decreto $\mathrm{n}^{\circ} 4.340 / 02$ foi alterada pelo Decreto $\mathrm{n}^{\circ}$ 5.566, de 26 de outubro de 2005, que passou a vigorar com a seguinte redação:

Art. 31. Para os fins de fixação da compensação ambiental de que trata o art. 36 da Lei $n^{\circ}$ 9.985, de 2000, o órgão ambiental licenciador estabelecerá o grau de impacto a partir de estudo prévio de impacto ambiental e respectivo relatório - EIA/RIMA realizados quando do processo de licenciamento ambiental, sendo considerados os impactos negativos e não mitigáveis aos recursos ambientais. (Grifos nossos)

Como se depreende da leitura do dispositivo, houve supressão da expressão "passíveis de riscos que possam comprometer a qualidade de vida de uma região ou causar danos aos recursos naturais”, que, de acordo com o artigo 31 do Decreto ${ }^{\circ}$ 4.340, de 2002, integrava o conceito de impacto ambiental para fins de pagamento da compensação. O novo texto parecia ampliar as lindes da competência do órgão ambiental para fixar a compensação.

Logo após, em 13 de fevereiro de 2006, foi concedida liminar em agravo ${ }^{1} \mathrm{em}$ mandado de segurança pelo Tribunal Regional Federal da $1^{\text {a }}$ Região, limitando a aplicação do percentual em relação à compensação ambiental em $0,5 \%$ para todos os empreendimentos passíveis de causar significativo dano ambiental. Em razão disso, em 15 de fevereiro de 2006, foi ajuizada no Supremo Tribunal Federal a Suspensão 
de Segurança $n^{\circ}$ 2.875, pelo Instituto Brasileiro do Meio Ambiente e dos Recursos Naturais Renováveis (IBAMA), alegando a legitimidade da fixação do percentual mínimo de 0,5\% e, além disso, a ocorrência de grave lesão à ordem e à economia pública.

Em 5 de abril de 2006, antes da apreciação da Suspensão de Segurança pelo STF, foi editada a Resolução CONAMA n ${ }^{\circ} 371$, que fixou o valor da compensação ambiental em 0,5\% dos custos previstos para a implantação do empreendimento, até que o órgão ambiental estabelecesse e publicasse metodologia para definição do grau de impacto ambiental (artigo 15). Assim, a resolução deu tratamento igual a todos os empreendimentos, sem considerar o grau de impacto ambiental causado pelos mesmos, acatando, na prática, o pleito do Mandado de Segurança deferido liminarmente pelo Tribunal Regional Federal da $1^{\text {a }}$ Região e objeto de pedido de Suspensão de Segurança.

Observe-se que, em 7 de abril de 2006, a presidência do STF houve por bem acolher a Suspensão de Segurança, deixando em vigor o percentual mínimo de 0,5\%, de acordo com o artigo 36 da Lei n ${ }^{\circ} 9.985 / 00$, apesar de a matéria já restar a rigor prejudicada, em virtude do tratamento em sentido contrário despendido pela autoridade normativa ambiental, através da Resolução CONAMA supracitada.

Dado esse quadro, voltemos ao exame da ADI n ${ }^{\circ}$ 3.378. Em sessão de 9 de abril de 2008, o Tribunal Pleno do STF julgou, por maioria, parcialmente procedente a ação, para declarar a inconstitucionalidade da expressão "não pode ser inferior a meio por cento dos custos totais para implantação do empreendimento", prevista no $\S 1^{\circ}$ do artigo 36 da Lei $n^{\circ} 9.985 / 00$. O valor da compensação, desse modo, deverá ser fixado proporcionalmente ao impacto ambiental, em consonância com o EIA/RIMA, quando serão assegurados o contraditório e a ampla defesa, nos termos da decisão do STF.

Verifica-se que o V. acórdão do STF inadmitiu a vinculação da base de cálculo da compensação ambiental ao custo total do empreendimento, haja vista que o montante de recursos há de ser compatível e proporcional ao grau de impacto ambiental causado pelo empreendimento. Sendo assim, o texto legal passou a ser: "o montante de recursos a ser destinado pelo empreendedor para esta finalidade, sendo fixado pelo órgão ambiental licenciador, de acordo com o grau de impacto ambiental causado pelo empreendimento".

Essa decisão se encontra atacada por Embargos de Declaração opostos por ambas as partes litigantes - Confederação Nacional da Indústria, autora, e Presidente da República, réu -, com pedido de efeitos modificativos do resultado do julgamento.

\section{QUESTÃO PRELIMINAR: A NATUREZA TRIBUTÁRIA DA COMPENSAÇÃO SNUC}

A compensação SNUC, como visto anteriormente, está positivada como uma prestação pecuniária obrigatória, devida ao Estado por empreendedores cujos 
empreendimentos sejam considerados, pelo órgão ambiental competente, de significativo impacto ambiental.

Assim, como hoje configurada, a hipótese em que é devido esse apoio financeiro ao Estado recai na definição de tributo do artigo $3^{\circ}$ do Código Tributário Nacional (CTN), que tem status de lei complementar, não podendo ser derrogado pela Lei Ordinária $\mathrm{n}^{\circ}$ 9.985/00. Prescreve o CTN, consolidando a doutrina universal a respeito, que "toda prestação pecuniária, em moeda ou cujo valor nela se possa exprimir, que não constitua sanção de ato ilícito, instituída em lei e cobrada por atividade administrativa permanente vinculada" é tributo.

Ora, a obrigação ex lege não deriva de uma ilicitude, pois o empreendedor atua na chamada "zona de tolerância”, que se situa a meio caminho da "zona livre" e da "zona proibida” de utilização da natureza (HERRERA MOLINA, 2005). Aliás, a Lei do SNUC invoca como seus fundamentos os incisos I, II, III e VII do artigo 225, § $1^{\circ}$, da Constituição Federal, e não o $\S 3^{\circ}$ desse dispositivo, que é aquele que funda o combate, por meio de sanções e reparações de danos causados, à ilicitude ambiental.

Desse modo, por se tratar de perda ambiental não mitigável, gerada pela ação lícita do empreendedor, objeto de licenciamento administrativo ambiental, não se pode falar em indenização de dano. Ademais, não se olvide que indenização só pode ser devida pela ocorrência de um dano real, efetivo. No entanto, a Lei do SNUC institui a necessidade de pagamento prévio, em dinheiro, em contemplação a um dano meramente potencial, não ocorrido, razão pela qual a sua natureza jurídica não pode ser considerada indenizatória, como é defendido por alguns (RODRIGUES, 2007).

Ora, a compensação SNUC é uma prestação legalmente obrigatória em dinheiro (obrigação de apoiar), não sendo destinanda a punir ilicitude, restando evidente, assim, a sua natureza jurídica de tributo.

Nesse sentido, a natureza tributária da compensação ambiental foi proposta pelo amicus curiae na ADI n ${ }^{\circ}$ 3.378, o Instituto Brasileiro de Petróleo e Gás (IBP). Contudo, esse tema fundamental trazido aos autos pelo IBP não foi sequer discutido pelo Supremo Tribunal Federal no julgamento da ADI, assim como não houve a apreciação da proposta feita pela Autora quanto à natureza jurídica indenizatória da compensação, devendo a omissão, desse modo, ser sanada de ofício pelo Tribunal, ao reavaliar a decisão embargada.

Ademais, a par de sua natureza genérica tributária, a compensação SNUC apresenta-se como imposto, tendo em vista que recai na respectiva definição doutrinária, positivada no artigo 16 do CTN, isto é, uma obrigação tributária que tem por "fato gerador uma situação independente de qualquer atuação estatal específica, relativa ao contribuinte". Em verdade, o fato gerador da compensação ambiental é um fato do contribuinte, qual seja, presumidamente causar degradação ambiental em função de um empreendimento. Além disso, a atuação estatal, no caso, faz-se em prol da comunidade, e não em face do empreendedor-contribuinte. 
Essa última verificação permite afirmar também que a compensação em questão não se apresenta como Contribuição de Intervenção no Domínio Econômico (CIDE), como defendido por parte da doutrina (GUERRA, 2005), porque não há grupo particular ("categoria específica de usuários") ao qual se estenda um benefício específico ou ao qual se dirija uma especial atuação estatal, pois esta consiste na criação de uma unidade de conservação que será usufruída por toda a população.

Trata-se, portanto, de típico imposto inominado, novo, que teria por fato gerador um significativo impacto ambiental ou a implantação de empreendimento que gere significativo impacto ambiental; em suma, a atividade contaminante, não mitigável (DOMINGUES, 2007). No direito constitucional tributário brasileiro, tal situação recai na competência residual de que trata o artigo 154, I, da Carta Magna, e, não possuindo "fato gerador ou base de cálculo próprios dos [impostos] discriminados” na Constituição, a compensação SNUC deveria ter sido prevista em Lei Complementar, o que não foi feito, dando-se assim a inconstitucionalidade formal do artigo 36 da Lei do SNUC.

\section{O DECRETO $\mathrm{N}^{\circ} \mathbf{6 . 8 4 8 / 0 9}$}

Um ano após a decisão do STF que considerou inconstitucional a fixação, para a compensação ambiental, do piso de $0,5 \%$ do custo total do empreendimento, e ainda pendentes de julgamento ambos os Embargos de Declaração acima citados, foi editado, em 14 de maio de 2009, o Decreto $n^{\circ}$ 6.848, visando à alteração dos artigos 31 e 32 do Decreto $n^{\circ} 4.340$, de 2002. Assim, passou a dispor o artigo 31 do regulamento da compensação SNUC:

Art. 31. Para os fins de fixação da compensação ambiental de que trata o art. 36 da Lei $n^{\circ}$ 9.985, de 2000, o Instituto Brasileiro do Meio Ambiente e dos Recursos Naturais Renováveis - IBAMA estabelecerá o grau de impacto a partir de estudo prévio de impacto ambiental e respectivo relatório - EIA/RIMA, ocasião em que considerará, exclusivamente, os impactos ambientais negativos sobre o meio ambiente.

$\S 1^{\circ} \mathrm{O}$ impacto causado será levado em conta apenas uma vez no cálculo.

$\S 2^{\circ} \mathrm{O}$ cálculo deverá conter os indicadores do impacto gerado pelo empreendimento e das características do ambiente a ser impactado.

$\S 3^{\circ}$ Não serão incluídos no cálculo da compensação ambiental os investimentos referentes aos planos, projetos e programas exigidos no procedimento de licenciamento ambiental para mitigação de impactos, bem como os encargos e custos incidentes sobre o financiamento do empreendimento, inclusive os relativos às garantias, e os custos com apólices e prêmios de seguros pessoais e reais. 
$\S 4^{\circ}$ A compensação ambiental poderá incidir sobre cada trecho, naqueles empreendimentos em que for emitida a licença de instalação por trecho.

Ademais, foram acrescidos ao Decreto n 4.340 , de 2002, os artigos 31-A e 31 B. O 31-A previu que o valor da compensação ambiental (CA) será calculado pelo produto do grau de impacto (GI) com o valor de referência (VR). OVR corresponde ao somatório dos investimentos necessários para a implantação do empreendimento, ressalvandose os investimentos previstos no $\S 3^{\circ}$ do artigo 31. Por sua vez, o GI poderá atingir os valores de $0 \%$ a $0,5 \%$, observados os critérios previstos no Anexo, quais sejam: o impacto sobre a biodiversidade, o comprometimento de área prioritária e a influência em unidades de conservação, calculados conforme os parâmetros estabelecidos no Anexo e de acordo com as informações previstas no EIA/RIMA.

Além disso, o artigo 31-B prevê a possibilidade de recurso da decisão do cálculo da compensação ambiental, no prazo de dez dias, dirigido à autoridade que proferiu a decisão, a qual, não a reconsiderando em cinco dias, encaminhará o recurso à autoridade superior, devendo esta julgá-lo em trinta dias, salvo prorrogação por igual prazo expressamente motivada.

Ressalte-se, ainda, que, apesar da retirada da expressão "não mitigáveis" do caput do artigo 31, que caracterizava os impactos ambientais negativos os quais ensejariam o pagamento da compensação, o seu $\S 3^{\circ}$ ressalvou a exclusão dos custos para a mitigação dos impactos ambientais do cômputo dessa compensação.

Isso posto, analisaremos algumas modificações trazidas pelo Decreto $\mathrm{n}^{0} 6.848$, de 2009, em relação à compensação ambiental.

\section{OS NOVOS CRITÉRIOS DE CÁLCULO DA COMPENSAÇÃO AMBIENTAL}

Conforme exposto acima, o artigo 31-A, acrescentado pelo Decreto $\mathrm{n}^{\circ} 6.848$, de 2009, previu que o valor da compensação ambiental será calculado pelo produto do grau de impacto (entre 0\% e 0,5\%) com o valor de referência, este correspondente ao somatório dos investimentos necessários para a implantação do empreendimento.

Assim, verifica-se que, em uma clara afronta à decisão do STF a qual declarou a inconstitucionalidade da expressão "não pode ser inferior a meio por cento dos custos totais para implantação do empreendimento", retirando da base de cálculo da compensação ambiental a noção de custo total do empreendimento e a referência ao percentual, o Poder Executivo acrescentou o artigo supracitado ao texto do Decreto $\mathrm{n}^{\circ} 4.340 / 02$, que regulamenta o artigo 36 da Lei $\mathrm{n}^{\circ} 9.985$.

Isso se depreende da instituição do critério "VR - valor de referência", que corresponde exatamente ao custo total do empreendimento, excluindo-se deste as medidas ambientais mitigadoras. Em outras palavras, em evidente violação ao princípio da separação de poderes, o Poder Executivo, através dos meios a ele atribuídos 
para editar normas regulamentares, retomou a consideração do custo do empreendimento no cálculo da prestação, bem como a aplicação de um percentual para este, ambas suprimidas através da decisão do Supremo Tribunal Federal em sede de controle abstrato de constitucionalidade.

Desse modo, o Decreto em questão apenas dissimulou os critérios julgados inconstitucionais pelo Supremo, através de subterfúgios, ignorando, assim, a imposição da fixação do montante dos recursos a serem destinados pelo empreendedor em consonância com o impacto ambiental negativo que possa ser gerado por seu empreendimento.

Nesse sentido, o Instituto Socioambiental (ISA) e a ONG Amigos da Terra Amazônia Brasileira, em 18 de junho de 2009, protocolaram a Reclamação n ${ }^{\circ} 8.465$, na qual alegam que o novo decreto afronta a decisão do STF, proferida na ADI $n^{\circ} 3.378 .{ }^{2}$

Sem prejuízo da crítica fundamental acima, é de se louvar a iniciativa do Decreto em questão de considerar como elementos de medição do significativo impacto ambiental, por exemplo, a influência em Unidades de Conservação, o impacto sobre a biodiversidade e o comprometimento de área prioritária, todos esses fixados de acordo com critérios minuciosos, estabelecidos no Decreto, o que representa, de certa forma, um avanço do administrador na tentativa de diminuir a insegurança jurídica causada pela ausência de critérios para o cálculo da prestação.

\section{A COMPETÊNCIA DO IBAMA, ÓRGÃO FEDERAL DE LICENCIAMENTO AMBIENTAL, PARA FIXAR O VALOR DA COMPENSAÇÃO SNUC}

Por outro lado, a nova redação do artigo 31, introduzida pelo Decreto n ${ }^{\circ} 6.848$, de 2009, prevê a competência do IBAMA - órgão administrativo encarregado da execução da Política de Meio Ambiente - para estabelecer o grau de impacto ambiental, de acordo com o EIA/RIMA, com o fim de fixar o valor devido a título de compensação ambiental.

De acordo com a Lei $n^{\circ} 9.985$, de 2000, e o Decreto ${ }^{\circ} 4.340$, de 2002, a competência para a fixação da compensação SNUC seria do "órgão ambiental” responsável pelo licenciamento ambiental, ou seja, não havia, no texto legal, distinção expressa de qual órgão licenciador seria competente para a cobrança da compensação.

Assim, a mudança introduzida pelo Decreto $n^{\circ} 6.848$ deixa clara uma limitação natural do âmbito de aplicação da compensação SNUC aos empreendimentos sujeitos a licenciamento pelo IBAMA.

No entanto, ressalte-se que não é qualquer empreendimento licenciado pela autarquia federal que pode ser obrigado a pagar a compensação SNUC. Apenas e tão somente aqueles empreendimentos que ontologicamente recaírem na competência (federal) exclusiva do IBAMA, ou seja, aqueles cujo impacto ultrapasse o território de determinado Estado, devem se sujeitar ao pagamento da compensação ambiental.

Ademais, a lei do SNUC preconiza uma receita pública, independente de qual seja sua natureza jurídica. Desse modo, como se trata de uma lei federal, esta só poderia 
prever uma receita federal, ou seja, determinado Estado ou Município não poderia pretender aplicar uma compensação SNUC local, com base na lei federal. Para que pudesse ser estabelecida a obrigação de pagamento de uma compensação ambiental no âmbito estadual, far-se-ia necessária previsão em lei estadual, sob pena de violação do princípio da autonomia financeira local (artigos 24 e 30 da Constituição Federal). E assim também na hipótese de se considerar a compensação uma indenização, pois, em se tratando de tributo, a competência para instituí-la seria privativamente federal ex vi do artigo 154, I, da Constituição da República.

\section{5 À GUISA DE CONCLUSÃo}

Sem prejuízo da análise da natureza jurídica da compensação SNUC, pelo ângulo tributário, que nos pareceria o correto (DOMINGUES, 2009), o histórico acerca do instituto demonstra uma série de evoluções e retrocessos na regência da matéria. Atualmente, com o Decreto $n^{0}$ 6.848, de 2009, verifica-se uma tentativa do Poder Executivo de manter, por meio do seu poder regulamentar, o tratamento pleiteado pela parte ré - Presidente da República - no bojo da ADI n 3.378, mesmo após decisão em sentido contrário do Supremo Tribunal Federal.

A compensação SNUC constitui importante fonte de receita pública federal e um encargo relevante para aqueles que pretendem implantar empreendimentos os quais causem significativo impacto ambiental, devendo, portanto, ser estabelecida de acordo com critérios determinados e estáveis, de modo a não violar a segurança jurídica indispensável ao administrado.

A declaração de inconstitucionalidade pelo STF, com redução de texto, em sede de controle de constitucionalidade concentrado, determinou que a base de cálculo da compensação ambiental não deveria se vincular ao custo total do empreendimento, mas ser fixada de acordo com o significativo impacto ambiental passível de ocorrência.

Apesar de os efeitos da decisão se encontrarem suspensos, em razão dos Embargos de Declaração opostos pelas partes autora e ré, não poderia o Poder Executivo, por outros meios, pretender fazer valer sua pretensão, como o fez, através do Decreto em questão. Desse modo, o Decreto n ${ }^{0}$ 6.848/09 representa uma clara afronta ${ }^{3}$ à decisão do Supremo Tribunal Federal, ao restabelecer a vinculação da base de cálculo da compensação ao custo total do empreendimento.

Não obstante, o Decreto $n^{\circ}$ 6.848/09 deixou clara a competência exclusiva do IBAMA para a fixação e cobrança da compensação SNUC, acabando com quaisquer dúvidas que poderiam surgir acerca de qual seria o órgão ambiental licenciador competente para tal.

: ARTIGo APRoVAdo (21/06/2010) : RECEBIDO EM 19/02/2010 


\section{NOTAS}

1 Agravo de Instrumento $\mathrm{n}^{\circ} 2005.01 .00 .060479-0 / \mathrm{DF}$.

2 Segundo Raul Silva Telles do Valle, Coordenador Adjunto do Programa de Política e Direito Socioambiental do ISA, um dos advogados que assinam a ação, "O Decreto n ${ }^{\circ} 6.848$ claramente contraria a decisão do STF, que diz que não se pode basear o valor da compensação no valor da obra, nem como piso e nem como teto” (ISA, 2010).

3 Contra: SILVA, Anderson Bitencourt, "Compensação Ambiental: Tributo ou Indenização por Danos Causados ao Meio Ambiente? Comentários ao Acórdão Proferido pelo STF no âmbito da ADIn n ${ }^{\circ} 3.378 /$ DF e ao Decreto Federal n ${ }^{\circ}$ 6.848/09), em Revista Dialética de Direito Tributário, São Paulo, v. 169, p. 7-20, 2009.

\section{REFERÊNCIAS BIBLIOGRÁFICAS}

DOMINGUES, José Marcos. O Supremo Tribunal Federal e a Compensação SNUC - A ADI 3.378-DF. Revista DIREITO GV, v. 5, n. 1, jan.-jul. 2009, p. 125-146.

. Direito Tributário e Meio Ambiente. Rio de Janeiro: Forense, 2007. p. 181-231, especialmente p. 199. GUERRA, Sérgio. Compensação Ambiental nos Empreendimentos de Significativo Impacto. Em WERNECK, Mário (Coord.). Direito Ambiental: visto por nós, advogados. Belo Horizonte: Del Rey, 2005. p. 129-46.

HERRERA MOLINA, Pedro Manuel. Princípios y Valores de la Fiscalidad Ambiental (Especial referencia a los tributos de tolerancia). Em CONGRESSO INTERNACIONAL DE DIREITO TRIBUTÁRIO DO RIO DE JANEIRO, 2005, Rio de Janeiro, Apresentação... Rio de Janeiro: Instituto de Estudos Tributários, 2005.

INSTITUTO SOCIOAMBIENTAL (ISA). ONGs vão ao STF para derrubar nova regra sobre compensação ambiental. 2010. Disponível em: <http://www. socioambiental.org/nsa/detalhe?id=2916>.

RODRIGUES, Marcelo Abelha. Aspectos jurídicos da compensação ambiental do art. $36, \S 1^{\circ}$ da Lei Brasileira das Unidades de Conservação (Lei 9.985/2000). Revista de Direito Ambiental, São Paulo, n. 46, 2007.

SILVA, Anderson Bitencourt. Compensação Ambiental: Tributo ou Indenização por Danos Causados ao Meio Ambiente? Comentários ao Acórdão Proferido pelo STF no âmbito da ADIn no 3.378/DF e ao Decreto Federal $n^{\circ}$ 6. 848/09. Revista Dialética de Direito Tributário, São Paulo, v. 169, p. 7-20, 2009.

\author{
Rua São Francisco Xavier, 524, 70 andar \\ Maracanã - 20550-011 \\ Rio de Janeiro - RJ - Brasil \\ jm.domingueslaglobo.com
}

Rua Oscar Valditaro, 94, apto. 604 Bairro da Tijuca - 22793-670 Rio de Janeiro - RJ - Brasil juliasacarneirolaterra.com.br
José Marcos Domingues

PROFESSOR TITULAR DE DIREITO FINANCEIRO DA FACULdADE DE DIREITO DA UNIVERSIDADE do Estado do Rio de Janeiro (UERJ)

\section{Júlia Silva Araújo Carneiro}

BACHARELADA EM DIREITO PELA UNIVERSIDADE do Estado do RIO dE JANEIRo (UERJ) 